\title{
PINTURAS RUPESTRES E PROBLEMAS DE CONSERVAÇÃo do SítIO EXPULSAR I, MUNICÍPIO DE QUITERIANÓPOLIS, CEARÁ, BRASIL
}

\author{
Lucineide Marquis ${ }^{1}$ \\ Heralda Kelis Sousa Bezerra da Silva ${ }^{2}$ \\ Bruna Gomes Brito ${ }^{3}$ \\ Sônia Maria Campelo Magalhães ${ }^{4}$ \\ Luis Carlos Duarte Cavalcante ${ }^{5}$
}

\begin{abstract}
Resumo: Neste trabalho apresenta-se o levantamento do sítio arqueológico Expulsar I, localizado no povoado Angical, área rural do município de Quiterianópolis, estado do Ceará, Brasil. Trata-se de um pequeno abrigo sob-rocha arenítica, cujas paredes e teto estão decorados com 140 pinturas rupestres miniaturizadas, representado antropomorfos (em sua maioria segurando propulsores e lanças ou fitomorfos), pegadas de aves (tridígitos), aves, cervídeos, fitomorfos, pé humano e grafismos abstratos (entre os quais bastonetes e conjuntos de dígitos). 18 manchas de tinta sem contorno definido também são observadas. As pinturas foram efetuadas predominantemente em diferentes tonalidades de cor vermelha, contudo, também ocorrem diversas figuras em amarelo, inclusive havendo motivos em bicromia. As figuras são delicadas e graciosas, tipicamente da Tradição Nordeste, em sua maioria compondo cenas e mostrando movimento e dinamismo. $O$ abrigo encontra-se em avançado estado de degradação natural, com o arenito se decompondo. O levantamento dos principais problemas de conservação também é discutido em detalhes.
\end{abstract}

Palavras-chave: Pintura rupestre; Tradição Nordeste; Expulsar I; Arqueologia; Ceará.

\footnotetext{
${ }^{1}$ Estudante da Graduação em Arqueologia e Conservação de Arte Rupestre/Universidade Federal do Piauí, Brasil. E-mail: lucineidemarquis@hotmail.com.

2 Estudante do Mestrado em Arqueologia/Universidade Federal do Piauí, Brasil. E-mail: dekelis.sousa@hotmail.com.

3 Estudante da Graduação em Engenharia Ambiental/Universidade Federal do Ceará, Brasil. E-mail: bruninhagbrito@gmail.com.

4 Doutora em História, docente e pesquisadora da Universidade Federal do Piauí, Brasil. E-mail: campelosonia2@hotmail.com.

5 Doutor em Ciências: Química, docente e pesquisador da Universidade Federal do Piauí, Brasil. E-mail: cavalcanteufpi@yahoo.com.br.
} 